\title{
O quefinda é o que fica: tradição em jogo, ensaio em xeque
}

\author{
What Ends is What Stays: Tradition at Stake, Essay Put in Check
}

\author{
Eduardo Ferraz Felippe \\ ffeduerj@gmail.com \\ Professor \\ Universidade do Estado do Rio de Janeiro \\ Rua São Francisco Xavier, 524, Maracanã \\ CEP 20550-013 - Rio de Janeiro - RJ \\ Brasil
}

\section{Resumo}

Este ensaio ilumina a atenciosa meditação de Lezama Lima acerca da tradição latino-americana. A princípio, diferencia-se da tradução cultural de Alejo Carpentier. Em seguida, em sua análise de T.S. Eliot e de Ernst Robert Curtius, relaciona tradição e historicidade, ao mesmo tempo em que coloca em seu centro o problema da experiência histórica, por meio da figura retórica da emulação. Por fim, esse conjunto de argumentos examina a visão histórica pela poesia como sua questão central. Inspira, assim, outros recursos para a historiografia por meio de sua crítica ao historicismo e a ênfase no reconhecimento.

\section{Palavras-chave}

Historicidade; Tradição; Ensaio.

This essay sheds light on Lezama Lima's careful assessment of the Latin American tradition. Firstly, it sets itself apart from Alejo Carpentier's cultural translation. Next, it relates tradition and historicity by analyzing T.S. Eliot and Ernst Robert Curtius, while it concentrates on the problem of historical experience by resorting to emulation as a rhetoric device. Last, but not least, these considerations assess the historical view by poetry as their central issue. They inspire, thus, other historiographical resources by means of their critique of historicism and their emphasis on recognition.

Keywords

Historicity; Tradition; Essay.

Recebido em: 3/8/2014

Aprovado em: 11/11/2014 
A escrita do ensaio que o leitor tem em mãos sugere certo vagar. 0 gênero híbrido a que normalmente é associado não deve ser tomado como linha de chegada, e sim ponto de partida para sugestões de invenção a partir de um nome consagrado a uma tipologia textual. Não se trata apenas da referência a uma matriz de gênero cujo vínculo entre conhecimento do mundo e de si, por meio do mise en forme, iniciou-se com Montaigne. Além da afirmativa consagrada, "os outros formam o homem; eu o relato" (MONTAIGNE 1965, III, p. 43), ${ }^{1}$ opto por investigar sua condição de forma insubmissa perante instâncias normativas, seja a religião, seja a ciência. A perda da totalidade veio conjugada à limitação do conhecimento como potência de um sujeito fadado à incompletude em sua busca incessante por aprofundamento da sua condição.

A ênfase na experiência fez com que, desde o início, o ensaio almejasse experimentar a si mesmo sempre de novo, o que relega o conhecimento adquirido a uma posição secundária. Conhecimento prévio e autoridade são alvos comuns aos quais se direciona o ensaio. No âmbito da dimensão crítica e da investigação histórico-literária, a tarefa de construir a tradição se completou com uma inquietude por renová-la. Ante a isso, o ensaio se insere em um horizonte amplo em que as definições limitantes a que esteve destinado no século passado talvez já não possibilitem escolhas contemporâneas. Em $A$ expressão americana (1957), a valorização da figura retórica da emulação desloca a discussão tão propalada das "belas letras" como descrição do ensaio para outro ancoradouro. Há aqui uma proposta destinada a elucidar os valores e prejuízos herdados da leitura dos clássicos para empreender uma apropriação mais genuína da tradição e proporcionar outra leitura do ensaio de Lezama Lima. ${ }^{2}$ Desse modo, acredita-se que suas linhas deixem de estar reclusas à imediatez da definição de "centauro de los géneros", conforme proposta por Alfonso Reyes ao ensaio, e possa estar ante os olhos a particularidade da sua forma escrita em relação ao passado.

Sem necessariamente tratá-la como um conceito (um agora, o termo; que demanda um futuro, a definição), a emulação endereça o problema da interpretação de textos, particularmente a questão da escrita e da leitura, ao território brumoso no qual se enfatiza a relação dialógica com o passado. A partir de uma textualidade própria, passa a estar em jogo, por meio de interrogações à tradição, a problematização dos critérios que presidem os limiares discursivos da história disciplinar, bem como a valorização da poesia enquanto parte possível do discurso histórico. Em suma, trata-se de toda a discussão acerca do uso da linguagem do historiador, em seu acontecer, e a criticidade da leitura que não pode ser reduzida à facticidade ou afirmação autoral acerca da "realidade" histórica. ${ }^{3}$

\footnotetext{
${ }^{1}$ No original: "Les autres forment I'homme: je le recite".

${ }^{2}$ Cabe considerar que Lezama Lima não foi inserido em importante antologia da produção ensaística do século XX por John Skirius (SKIRIUS 1994), justamente por sua forma difícil.

3 Aqui há uma ampla fortuna crítica destinada ao estudo do tema. Destaco o livro de Dominick LaCapra. Rethinking Intellectual History. Texts, Contexts and Language.
} 
Em artigo recentemente traduzido para o português, Frank Ankersmit, ao analisar o desacordo entre a linguagem e o mundo, ponderou que a "linguagem histórica" é o recurso que temos (ANKERSMIT 2012, p. 61). O ensaio não é documento e nem reduz o texto a pretexto de uma leitura sem conexão ao que se apresenta ante os olhos. A escrita ensaística sugere o ato da leitura e o endereçamento para o futuro de uma escrita fincada na historicidade do historiador em seu presente. Se a questão da linguagem histórica permite conceber a "...inelutável verdade de que a história não é uma ciência e ela não produz conhecimento no sentido próprio da palavra" (ANKERSMIT 2012, p. 38 ), trata-se de conceber os dilemas envoltos no tema da tradição como uma imagem diretriz. Não se aventa a contrapartida da autônoma determinação, mas o paradoxo que a vincula à autoridade insubmissa associada ao acontecer humano por meio do diálogo entre tradição e ensaio em um desejo permanente de reconhecer-se. Antes de um momento novo do que tem sido a relação humana com o passado, sugere-se a produtividade hermenêutica de um saber-se cônscio das múltiplas vozes em que ressoa o passado no mistério humano. Cegos diante da luz, apenas vendo o iluminado, oferta-se a sugestão de que a consciência histórica em sua busca pelo objetivismo histórico apagou a contribuição da tradição em uma tarefa que nunca se cumpre por completo, a compreensão, e, por isso, cai e se levanta em tentativas infindas. Tudo isso sugere imensidão e enigma. Talvez por isso haja a admiração explícita de Lezama Lima por Herman Melville e o símbolo da baleia a sugerir infinito e procura sem nunca alcançar 180 plenamente o almejado.

\section{A fiação de Carpentier: o par tradição/tradução}

Os textos voltados à compreensão da tradição costumam analisá-la por meio do conceito de ruptura como caminho para o novo. O texto mais conhecido é "A tradição e a época moderna" de Hannah Arendt (ARENDT 2002). Ao buscar compreender a experiência totalitária, Arendt concebe a contemporaneidade como o ponto de chegada de um percurso que pôs por terra a tradição, a autoridade e a religião. A autora não encontrou no passado algo que pudesse sussurrar um fio com o presente desta experiência política. ${ }^{4}$ A falência de uma concepção de mundo centrada no valor do futuro, em sua confiança no progresso técnico-científico, enfatizou uma experiência de tempo de desmedido valor do presente. ${ }^{5}$

A inquietação de Alejo Carpentier, presente no artigo "América ante a jovem literatura europeia" (1931) sugere os diversos modos como a tradição americana deve se reinventar para dar conta do presente. Considera que somente a ruptura com a Europa não daria conta da constituição de um novo horizonte para a América:

\footnotetext{
${ }^{4}$ Outros textos, porém, como é o caso de Peter Burke, ao analisar o conceito de decadência em Gibbon, entendem a tradição como limitadora das possibilidades expansivas do homem, especialmente pela diminuição do valor da experiência que a ela subjaz (BURKE 1992, p.176-195).

${ }^{5}$ Exemplo disso está em Eduardo Jardim que, em um diálogo ficcional, sugere que tanto Hannah Arendt quanto Octavio Paz enfatiza a ruptura com a tradição e a busca por novas referências epistemológicas (JARDIM 2007).
} 
Não basta dizer "cortemos com a Europa" para começar a oferecer expressões genuinamente representativas da sensibilidade latino-americana. Toda arte necessita de uma tradição de ofício. Em arte, a realização tem tanta importância como a matéria prima de uma obra (CARPENTIER 1931, p. 52, grifos do autor).

Para Carpentier, a ausência da tradição demonstra a fragilização da América Latina ante o continente europeu e a preocupação com um determinado passado comum latino-americano. A tradição, em suas palavras, é uma ausência e uma inquirição, um horizonte a ser construído e a ser ressignificado. A demanda por uma tradição é intensa e reitera a necessidade de realização. A continuidade do artigo é sugestiva:

Por isso, é fundamental que os jovens da América conheçam a fundo os valores representativos da arte e da literatura moderna da Europa. Não para realizar um trabalho desprezível de imitação e escrever, como fazem muitos novelistas... por meio de cópias de modelos do além-mar, e sim para buscar chegar ao fundo das técnicas, por meio da análise, e descobrir métodos construtivos aptos a traduzir com maior força nossos pensamentos e nossas sensibilidades (CARPENTIER 1931, p. 53).

Ter controle das técnicas inauguradas pelas vanguardas parisienses é a condição para produzir algo próprio. Carpentier nega a imitação, mas propõe que a relação de contato com as técnicas europeias não seja deixada para trás. Trata-se de lapidar o alheio no âmbito da própria tradição. A imitação ou a cópia contrapõe-se à abertura feita pela tradução. Está posto assim um tema subjacente a todo o texto que o leitor tem em mãos: a engenhosidade que uma cultura não hegemônica elabora para se afirmar ante uma cultura hegemônica. Ao fim, o que se propõe é: o deslocamento da imitação implica na centralidade da tradução. Não se trata de fechamento ao forâneo, e sim de abertura cônscia na periferia. Carpentier, ao citar o contato com Rivera, ilumina o cruzamento de muitos autores que já se dedicaram a pensar o âmbito do próprio e do externo: "Quando Diego Rivera, homem em que palpita a alma de um continente, nos diz: 'Meu mestre, Picasso'"' (CARPENTIER 1931, p. 56).

A tradução é um modo de percepção da América e de sua manifestação escrita peculiar, e é um tema eleito por Carpentier em sua ênfase na técnica. "Conhecer técnicas exemplares para tratar de adquirir uma habilidade paralela e mobilizar nossas energias em traduzir a América com a maior intensidade possível: tal haverá de ser sempre nosso credo pelos anos - mesmo que não disponhamos de uma tradição de ofício" (CARPENTIER 1931, p. 57, grifos do autor). A relação estabelecida entre a tradução e a tradição, particularmente produzidas por Carpentier, operam dentro de um rigor de estilo, enfatizado dentro de sua obra, mas que obedeciam, ainda, ao que de particular pudesse ser observável na América. ${ }^{6}$

\footnotetext{
${ }^{6}$ Essa é uma singularidade na fortuna crítica do autor. De um modo geral, valorizou-se seu vínculo com o surrealismo (BIRKENMAIER 2006, p. 25-87) ou sua relação com o quesito nacional (GONZALEZ ECHEVARRÍA 2009, p. 155-213).
} 
A autossuficiência provém da capacidade de escolha - de selecionar ambiências, figuras e traços daquilo que já havia sido produzido alhures. A repulsa pela tradição, de algum modo, dialoga com o culto ao progresso. Nesses autores, há uma frequência de diálogo que designa uma dúvida, uma ambivalência, mais do que rejeição ou cópia pura e simples. A fertilidade desse argumento sugere a singularidade dos autores, sendo que, por tradição, não se deve entender apenas aquilo que ocorre no âmbito externo ao continente americano, mas também o vínculo apropriativo com a leitura de autores hispano-americanos, como José Martí, e um posicionamento político de se inserirem enquanto parte do Ocidente.

Essas indagações somente ganhariam forma por meio do contraponto ao ambiente decadente europeu, presente em seu artigo "El ocaso de Europa" (CARPENTIER 1941). Tanto Carpentier quanto Lezama Lima foram influenciados pelo cenário posterior à Segunda Guerra Mundial e as desconfianças frente ao continente que ameaçava ruir, o que explicita a historicidade da discussão. Ao mesmo tempo, a leitura enviesada da tradição desloca a centralidade de uma experiência de mundo ainda fortemente influenciada por um sujeito autocentrado para outras possibilidades de escrita e leituras em que se coloca em seu centro a retórica com o fito de compor um ensaio calcado no discurso histórico, tributário da tradição poética inglesa e da indagação filológica alemã de autores como Ernst Robert Curtius.

\section{Lezama Lima e a questão da emulação: o par tradição/poesia}

182 Lezama Lima, em seu belo ensaio La expresión americana (1957), apresenta o passado por meio de uma elaboração particular, voltada a expor, de modo próprio, um conjunto de circunstâncias e problemas da experiência humana. Leitor voraz, utilizou o poema Quatro quartetos (1943) de T.S. Eliot para desenvolver a relação entre a tradição e a contemporaneidade, tendo como preocupação central a questão da articulação entre as temporalidades. Retirado da sua referência original com "East Coker", Lezama Lima desloca e ancora suas indagações em outro lugar. Conforme sua particular citação de T.S.Eliot:
[...] e o que há por conquistar
Pela força ou submissão, já foi descoberto
Uma ou duas, ou várias vezes por homens que jamais/poderemos
Emular - mas não há competição -
Só há luta para recuperar o que foi perdido.
E encontrado e outras vezes perdido: e agora, em condições
Que não parecem propícias. Mas talvez sem ganhos ou perdas
(LEZAMA LIMA 1988, p. 56).7

Um anseio inalcançável, uma perda irrecuperável, uma certeza inefável. A emulação não trata do lugar de encontro em uma figura perdida e imediatamente recuperada. Em outro diapasão, a apreensão dessa estratégia

\footnotetext{
7 No original: "[...] And what there is to conquer/ By strength and submission, has already been discovered/ Once or twice, or several times, by men whom one cannot hope/ To emulate - but there is no competition There is only the fight to recover what has been lost/ And found and lost again and again: and now, under conditions/ That seem unpropitious. But perhaps neither gain nor loss" (ELIOT 2004, p. 334).
} 
retórica como distinta para a relação com a tradição europeia é incorporada dentro do discurso de Lezama, dando-Ihe a feição de uma inovação caracterizada pela sutil beleza e potencial crítico de sua escrita. A leveza de suas palavras pode esconder a ambição da proposta: a tradição não é uma carga que a América incorpora. "Para nós, só há a tentativa. O resto não é de nossa conta" (LEZAMA LIMA 1988, p. 56). É herança, não legado, imersa em um coser e descoser eternos.

A beleza dos Quatro quartetos fala por si mesma em diversas estrofes. Cabe recortar a passagem inicial lida por Lezama Lima. "O tempo presente e o tempo passado/estão ambos talvez presentes no tempo futuro/E o tempo futuro contido no tempo passado/ Se todo o tempo é eternamente presente/ Todo o tempo é irredimível" (ELIOT 2004, p. 332). ${ }^{8}$ A questão do tempo, cerne da experiência humana, explicita-se, em T.S. Eliot, não enquanto um modo de perceber a diferença, tão caro aos estudos antropológicos; pelo contrário, ele é a marca de um (re)conhecimento vocacionado a um instante de perfeita unidade e contemplação.

Há uma extensa e rica fortuna crítica que se debruçou sobre a obra de T.S. Eliot. Não cabe mencionar todos aqueles que, com cuidado e apreço, estiveram vocacionados, por um lado, a compreender traços de seu percurso biográfico e, por outro lado, dedicar-se à análise formal de sua construção poética. ${ }^{9}$ Lúcido e lúdico, Lezama Lima incorpora partes daquilo que Ihe foi sugerido pela forma poética de T.S. Eliot com especial atenção ao contraponto alegórico. A construção contrapontística, característica de uma poética do fragmento, marca poética de Eliot, foi explicitamente incluída nas produções poéticas posteriores de Lezama Lima, como, por exemplo, "Noite insular, jardins invisíveis".

Toda a elaboração escrita de Lezama Lima está centrada na permanente relação entre analogia e correspondências como forma de reinventar relações de espaço e tempo. Indagação central da obra de T.S. Eliot, presente de modo latente em Quatro quartetos, o contraponto e as remissões analógicas são pistas para uma construção fragmentária que não se resolve em si mesma, mas que expressa um mistério impronunciável. A miscelânea de tempos e esse pendor ao inefável marcam a sua poesia ao mesmo tempo em que, ao ser incorporado por seus leitores, abrem espaços propícios ao que não será exatamente explicitado. Em (des)leituras possíveis, o que permanece é o que fenece em outra língua como um morto a ganhar vida após o embalsamento endereçado à eternidade.

Apesar de toda a obra ser importante para o escrito que o leitor tem em mãos, Quatro Quartetos explicita o equilíbrio entre silêncio e comunicabilidade cobiçado por Lezama. Em sua apresentação, o poema está fundado na questão da temporalidade humana. Por vezes na leitura do processo histórico, por outras de uma experiência individual, Eliot busca, em meio à efemeridade das coisas, o instante em que as dissonâncias se anulam por meio do desenvolvimento escrito

\footnotetext{
${ }^{8}$ Em Four Quartets: "Time present and time past/ Are both perhaps present in time future/ And time future contained in time past/ If all time is eternally present/ All time is unredeemable" (ELIOT 2004, p. 332).

9 Chiampi valoriza a questão da imagem para Lezama Lima (CHIAMPI 1998). Já Ingrid Robyn enfatizou a questão da herança vanguardista (ROBYN 2012).
} 
da experiência do tempo complexo: "No ponto imóvel do mundo em movimento, nem a carne, nem a ausência da carne, nem de, nem para onde, no ponto imóvel lá está a dança. Mas nem parada, nem em movimento" (ELIOT 2004, p. 337). Há aqui uma via mística em que o movimento disfarça a eternidade contida na variação daquilo que se expressa como fluidez do tempo, jamais plenamente apreendida. A "dança" é o alvo jamais alcançado de modo pleno, mesmo ao ser encontrada, "nem parada nem em movimento".

A epígrafe dos Quatro quartetos, fincada na transitoriedade de toda experiência humana é o texto estabelecido por $\mathrm{H}$. Diels, Die Fragmente der Vorsokratiker, notabilizada pela afirmativa de Heráclito: "O caminho que sobe e o caminho que desce são um único e mesmo". Há um fundamento místico, apreendido também por Lezama Lima, em que a busca reside em libertar o espírito humano de suas limitações temporais nas quais a ação contemplativa e a ação ativa são parte de uma atitude prática e problemática em relação ao problema do tempo. O poeta inglês pressupõe que existe uma profunda unidade por trás da explícita diversidade - a experiência humana, passível de ser surpreendida na pluralidade de tempos e espaços ao invocar o símbolo e a analogia. "Em meu princípio está meu fim. Uma após outras/ as casas se levantam e tombam, desmoronam, são ampliadas/ Removidas, destruídas, restauradas, ou em seu lugar/ surgem um campo aberto, uma usina ou um atalho" (ELIOT 2004, p. 349). Fim e princípio em um mesmo instante - a possibilidade permanente de ampliação da experiência humana sem demandar uma resposta divina.

Lezama Lima, leitor de Eliot, dá uma nova nota em sua reescrita, face a face com o autor norte-americano. Talvez a excessiva atenção dada à discussão do neobarroco, justificada devido ao impacto na obra do autor insular, tenha mascarado um pouco diferentes alternativas e questões aos seus estudos (CAMPOS 2002). A valorização da tradição, em sua leitura de Ernst Robert Curtius, e a forma poética, com sua predileção por T.S. Eliot, é parte central dessa tentativa de reler esse rico autor colocando em seu centro as indagações acerca da historicidade. Ao comentar, ainda, Quatro quartetos, afirma "...crê que os mestres antigos não podem ser superados, restando apenas a fruição de repetir, talvez, com novo acento" (LEZAMA LIMA 1988, p. 56).

Por via de sua leitura do ensaio de T.S. Eliot "Tradition and individual talent" (1919), Lezama concebe que toda escrita não deve esquecer o passado, o gesto fundador da leitura e a necessidade de pensar a usurpação constitutiva da tradição. O trecho que sugere a fina atenção de Lezama Lima reside em "As gerações não se formam na vontade de querer o diferente, que é a aparência, mas no ser da criação, de ente concorrente do que é verdadeiramente novo" (LEZAMA LIMA 1957, p. 163). Renovado pelo antigo, somente se dá enquanto novo, de novo. Sucintamente termina por distinguir, para Lezama Lima, a importância e o valor da novidade enquanto a forma e a utilização da linguagem dada pela incorporação seletiva do precedente. 


\section{O que finda, o que fica}

A figura retórica sugere um olhar enviesado da tradição. Olhos nos olhos, fica a pergunta: Qual a singularidade dos ensaios frente ao que havia sido proposto pela tradição europeia? A lida com a tradição, longe de ser um fardo, é uma fiação mergulhada no presente com o olhar enviesado ao futuro atento ao antecedente. Somente esse precedente maior, rival que não deixa nunca de estar próximo, uma espécie de alma forte que liberta e oprime, insere o escritor nessa tradição comum que o liberta da armadilha do solipsismo. Tributário da força precedente, a inventividade repousa no excesso ao pagamento das dívidas. A tudo isso, o nome tradição não acabrunha nem ancora o passado, mas o expande por veredas ainda não rascunhadas por um mundo sem destino prévio.

A destinação ainda está atrelada a um problema anterior: como a modernidade lidou com a herança que Ihe foi recebida, sem o dilema da exemplaridade. Por modernidade entende-se, a partir de Habermas, o instante em que houve o nascimento da reflexão sobre ela, com Hegel, ao elevar o processo de separação dessa modernidade a um problema conceitual (HABERMAS 1988). A época moderna deixou para trás a capacidade pedagógica da História, tal como definida pelos marcos tradicionais da 'história mestra da vida' (KOSELLECK 1993). As condições materiais da vida não eram as únicas a se modificar, mas também a própria natureza humana, justamente pela conjunção entre progresso e perfectibilidade da razão que, a partir da modernidade, passaram a ser os referenciais seguros para o entendimento da mudança histórica. O descolamento entre horizonte de expectativas e experiências pregressas legou ao espírito humano uma desconhecida insegurança, fruto do caráter dessemelhante entre os dois tempos. Na modernidade, sob esse processo de temporalização e singularização da história, houve a ruína dos pressupostos trans-históricos que eram o alicerce da tradicional 'historia mestra da vida'. A perda de orientação do passado veio atrelada ao reconhecimento de que à tradição podem ser agregadas novas circunstâncias.

Se a Aufklärung colocou em oposição excludente autoridade e razão, o antigo passa a ser combatido e contraposto em sua prévia aceitação. Do contraste entre ambas as categorias, o resultado derivou para o preconceito a favor do novo como o perfil final da querela entre os opostos, ou seja, a soberba da razão em relação à autoridade. A compreensão romântica da tradição opõe-se ao princípio da Aufklärung; pois, contraposto à liberdade racional, o romantismo entende a tradição como uma naturalidade humana (CALINESCU 1987).

A legitimação da presunção da razão deriva do instante em que se entende a contraposição como produtora de preconceitos; contudo, ao deslocarmos a luz para uma produção de verdade, como faz Lezama Lima, a questão é outra. O enriquecimento da forma, não mais vinculado ao exercício de reconstrução do passado e submissão do presente, faz com que a autoridade se reinvente por meio da aproximação ao (re)conhecimento. Não se outorga autoridade ao precedente; adquire-se. Um aceno em direção à sobrevivência ante a volubilidade da vida, como Lezama Lima faz com T.S. Eliot. 
Ao analisar de forma específica a tradição, dá encaminhamento à proposta:

Eis aí a prova mais decisiva, quando um esforçado da forma recebe um estilo de grande tradição e, longe de diminui-lo, devolve-o enriquecido, símbolo de que este país alcançou a sua forma na arte da cidade (LEZAMA LIMA 1998, p. 104, grifo meu).

Creio que a passagem selecionada explicite o que se quer acentuar. $O$ enriquecimento por meio da ação de reescrever, novamente, mas com o sentido mais elevado, tudo aquilo que se consegue apreender do cânon por meio de um estilo próprio. Repousa na ordem do reconhecimento, e não da epistemologia, a atribuição de um lugar, encarecido, a outro. Desestabilizar o cânon é reenviá-lo enriquecido, reformado, como uma contribuição ao prévio, sem que se entenda enquanto obediência cega ao comando. As belas linhas de A expressão americana (1957) estão vocacionadas a propor o desvínculo entre tradição e autoridade com o fito de abrir uma brecha para a presença da imaginação como apanágio da ambivalência de sua inscrição no mundo dos homens. A fiação daí derivada, em sua desmedida e riqueza, tem como produto o reconhecimento de um lugar e de uma proposta que se efetiva por meio da figura retórica da emulação. A produtividade dessa leitura abre o horizonte a algo novo, em se tratando do tempo e dos modos de fazer. Não se trata da antropofagia de Oswald de Andrade ou da tradução cultural de Alejo Carpentier, vinculadas à discussão cultural do início do século XX, mas do aprofundamento de uma questão gestada ao longo de todo esse século e que encontra seu recanto ao pensar somente após a Segunda Guerra Mundial, no instante em que a América ganha um sopro novo.

Em outro ensaio, dentro do conjunto de ensaios - que tangenciam a história, a memória, a literatura, a ficção e a Antropologia - este modus de escrita torna-se mais claro: "Crê romper com a tradição, quando a engrandece. Assim, quando acredita ter se separado do hispânico, reencontra-se nele engrandecido" (LEZAMA LIMA 1998, p. 113). Mais uma vez, uma pergunta capital: por que seria produtiva a presença da figura da emulação? Não se trata simplesmente de estilo, como uma belle lettre que gerasse um ensaio em um modelo híbrido entre literatura e história / entre ciência e literatura, já tão comentado por autores como Adorno e Lukács. ${ }^{10}$ A leitura de T.S. Eliot por Lezama Lima é produtiva ao operar um deslocamento, tendo como centro a emulação, que o (des)associa da compreensão romântica acerca da tradição como contrapartida abstrata da autônoma determinação.

O discurso de Lezama Lima (1998, p. 113) indica: "Reformar dentro da ordenação prévia, não romper, mas retomar o fio, isso é que é hispânico. Frei Sevandro o espuma e acresce...". A valorização da tradição por Lezama e sua permanente intenção de dissociar tradição de obediência invalidam qualquer oposição incondicional entre razão e tradição. Antes, há uma crítica própria, que se volta de novo para a verdade da tradição e procura renová-la, ao encontrar o fio sem que tenha que sustentar o fardo em uma fiação

$\overline{10}$ Trata-se dos ensaios de ADORNO 2003; e LUKÁCS 1974, especialmente Cap. 1, 3 e 6. 
cujo nome tradicionalismo não seria descabido. Se nas mudanças históricas a tradição como conservação está presente, ela não deve ser confundida com a ausência de sentido por não atrair a atenção sobre si. Em outro diapasão, conservação, inovação e destruição unem-se em uma conduta portadora da liberdade inerente à finitude humana.

A beleza da passagem possui o tom conclusivo, tanto para o ensaio quanto para tudo o que se refere ao modo de relacionamento com o passado: "Criador, em meio à tradição que desfalece, obriga-se à síntese de ruptura e secularidade..." e o escritor, tendo visões projetivas, articula-as ao pretérito imperfeito de sua condição humana: "a afastar-se da tradição que se resguarda para reencontrar a tradição que se expande. Joga e percorre destinos" (LEZAMA LIMA 1998, p. 113).

Em inúmeras passagens, os temas tornam-se recorrentes, impulsionados por uma tentativa permanente de incorporação e enriquecimento, e, em um grau mais profundo, uma abertura ao (re)conhecimento. Uma das passagens significativas e determinantes do conjunto de ensaios pode ser apreendida em

\begin{abstract}
Esse centro temático tinha que surgir de uma nova formulação: que Picasso, na história da cultura plástica, havia entregado e tornado visíveis alguns segredos muito importantes, tais como elementos plásticos, astúcias de composição e o descobrimento, em sua plenitude da tradição verdadeiramente criadora na plástica. O que foi uma busca dolorosa em Cézanne, com bem poucos discípulos, em Picasso convertia-se num perene encontro, em venturas, afortunadas possibilidades (LEZAMA LIMA 1957, p. 158).
\end{abstract}

A imagem conhecida de Picasso e Cézanne sussurra algo: o fio de continuidade supera o fardo de tempos pretéritos. O afortunado encontro de Picasso com Cézanne é mais do que uma influência: é a tradição em si. Somente reconhecível por uma luz vindoura, sua aura de autenticidade recai em um presentificado instante quando o porvir, Picasso, abre a clareira ao seu precedente, Cézanne. A perenidade do encontro se dá na medida de um (re) conhecimento do outro em si, em um instante no qual o prévio já estivesse permanentemente na forma final. Estar imerso na tradição não significa em primeiro plano estar submetido a preconceitos e estar limitado em sua própria liberdade. A vereda aberta pela discussão acerca da tradição permite ao homem entender-se enquanto um estranho de si mesmo, cônscio da tarefa histórica de habitar o finito que não pode ser apagado dos rastros humanos.

\title{
O ensaio, a ficção e a história a partir de Lezama Lima
}

Nesse caminho de leitura, que não se reduz à análise, do texto de Lezama Lima, algumas questões se evidenciam, enquanto outras enturvecem. Em diversos momentos, como já havia exposto Irlemar Chiampi, Lezama direciona toda a sua crítica a um lugar preciso: o historicismo (CHIAMPI 1988). Não que o faça por meio de um permanente esquadrinhamento de ideias, desfazendo a colcha de retalhos da intriga de outros autores, como Hegel. O que se tem em mãos é outra coisa. 
Leitor de Carpentier e das críticas acerca da particularidade cultural latinoamericana, em princípios da década de 1930, Lezama Lima consegue fazer um deslocamento rico, por tudo aquilo que mostra, e por tudo aquilo que esconde. Se Carpentier ainda está preso aos quadros de uma incorporação cultural, em diálogo profundo com Oswald de Andrade e seu conceito de antropofagia, Lezama Lima entende a tradição e a relação geracional com outro acento. Ao recortar três grandes autores pertencentes às vanguardas históricas - Stravinsky, Picasso e James Joyce -, menciona que o esprit nouveau vanguardista assinalou sua inquietude por meio do modo como se utilizou do fio deixado por autores pretéritos. "Picasso era "outra coisa", diversa da busca da sensação; Stravinsky era "outra coisa", diversa do afã de encontrar a "cor orquestral". Um Joyce era "outra coisa", diversa da sátira moral de um Bernard Shaw" (LEZAMA LIMA 1957, p. 161). A reinvenção proposital das formas de escrita feita pela geração vanguardista, em seu afã de destacar a ruptura, não pode deixar para trás a dívida geracional. Lezama clama para que o fio e o fardo se equilibrem em uma escrita que incorpora o forâneo, o alheio, e constitui, de modo cônscio, a tradição.

Ao perceber sutilmente a singularidade da dimensão inventiva em sua lida com o passado, por meio do ensaio, consegue tangenciar tanto aquilo que ataca o verídico, quanto aquilo que se supõe falso.

Na realidade, o que se sucedia em sua nova e verdadeira profundidade era mais difícil de ganhar e mostrar. Sobretudo porque era uma nova posição, desamparada de qualquer historicismo, não precisada por referências anteriores. Na minha opinião, devia-se ao surgimento de uma nova manifestação do homem em sua luta com a forma (LEZAMA LIMA 1957, p. 164).

O ataque ao historicismo é um ataque mais amplo, cujo alvo não pode ser completamente alcançado. Trata-se de um modo de compreender o tempo ao não ser mais entendido como o que separa, mas é a condição do acontecer em sua "nova e verdadeira profundidade". O que se ganha e o que se perde, como em um jogo em que o praticante tem autoconsciência de seu posicionamento e de que tudo aquilo em que está imerso, não passa de uma ilusão que irá se desfazer diante de seus olhos. "Ganhar" e "mostrar" são difíceis ante a orfandade humana desprovida de um senso de certeza que a preceda. Novidade, nesse caso, não deixa de estar associada ao precedente nem à tradição, mas desloca um senso de real voltado ao legado que não foi "precisado".

A pressuposição do historicismo de que era necessário ir em direção ao espírito de época, pensar suas características próprias e somente assim alcançar a objetividade histórica, limita as potencialidades humanas. Lezama Lima escolhe Herman Melville e Whitman como dois libertários do historicismo por meio da retomada da tradição do ocidente para um "recomeço" americano. Pensar com os conceitos e representações de uma determinada época é um objetivo ingênuo que limita a "nova manifestação do homem" em sua labuta diária. O tempo como fundamento, e não como abismo a ser transposto, desloca o historicismo para que a nova manifestação humana se erga em sua 
"Iuta com a forma" (LEZAMA LIMA 1988, p. 56). O ensaísmo é um princípio que emerge na obra como movimento que a anima sem a intenção de atingir uma síntese.

Nesse sentido, Lezama Lima, em leitura enviesada, incorpora de Eliot apreciação destacável: "Eliot pretende... não aproximar-se de novos mitos... mas ao resguardo que oferecem esses mitos às obras contemporâneas, que lhes dão uma espécie de nobreza clássica" (LEZAMA LIMA 1988, p. 56). Contudo, do autor inglês também destoa: "Quisera que o nosso método se aproximasse antes dessa técnica da 'ficção', preconizada por Curtius, que do método mítico-crítico de Eliot" (LEZAMA LIMA 1988, p. 57). Trata-se da "fabulação criadora", proposta por Curtius em que se coloca em cena o "antagonismo entre as gerações característico de todas as épocas agitadas" (CURTIUS 2013, p. 141). Ou, nas palavras de Lezama Lima, "tudo terá de ser reconstruído, invencionado de novo, e os velhos mitos, ao aparecerem de novo, nos oferecerão seus conjuros e seus enigmas com um rosto desconhecido" (LEZAMA LIMA 1988, p. 57).

Enquanto entes históricos, nosso comportamento com relação ao passado, confirmado em nossa cotidianidade, não pode ser visto de modo contraposto, pura e simplesmente, aos artefatos que criamos por meio da invenção. $O$ que está em questão, no ordinário do mundo, não é o distanciamento nem a liberdade em relação ao recebido. Em meio a tradições, como estamos agora eu e você, não conseguimos perceber o estranho ou alheio, posto que algo próprio, intimidante e íntimo, exemplar ou postulável, abre-se a um reconhecer-se, no qual já não se divisa ou percebe.

O desarrimo do homem no mundo é o reduto de sua grandeza não definível de modo prévio por tudo aquilo que o antecede ou incorpora. "Era um tipo de criador que podia ser, ao terminar sua primeira formação, nutrido por toda contribuição da cultura antiga, que longe de fatigá-lo, exacerbava suas faculdades criadoras, fazendo-as terrivelmente surpreendentes" (LEZAMA LIMA 1957, p. 164). A distância temporal é nutriente de uma ação que re-vela, novamente põe o véu, sobre a objetividade histórica, em seu desejo permanente de encontro com algum pórtico plenamente seguro. Está preenchido pela seletividade consciente da tradição e da continuidade histórica, cuja iluminação é mostrada no transmitido. Não há padrões seguros dados pela distância temporal, posto que sempre se está enredado em um instante de velamento; pelo contrário, o que se percebe é a produtividade do acontecer. A ausência de segurança é dada pela conjunção entre a impotência do juízo e tudo aquilo que se recebe enquanto herança. Novo, novamente; a cultura antiga não pesa sobre os ombros. Deixa de ser o excesso, como areia jogada a um morto em um ritual fúnebre. Tendo em seu centro o (re) conhecimento, por meio da emulação, desloca-se a centralidade da seleção e se sugerem os impasses da percepção e do juízo. Talvez por isso o problema da mente seja tão importante para Lezama Lima em Paradiso.

A ênfase proposta por Lezama Lima para a figura da emulação o aproxima de uma abordagem historiográfica, deslocando-o de produções associadas ao estudo da cultura latino-americana, unicamente, e endereça seu nome à contemporaneidade daqueles em busca de novas formas de indagação do 
ensaio em sua seletiva leitura da história em sua "queda na linguagem". ${ }^{11}$ Não se trata da emulação como poética, mas de uma leitura que a coloque em centro de novos sentidos para a história intelectual. ${ }^{12} \mathrm{O}$ retorno da emulação ao seu sentido originário, com Aristóteles, desloca o problema de uma história das ideias repousando a questão na dimensão dialógica e suplementar dos textos com o passado. Se em Retórica, Aristóteles considera que o sentido da emulação está voltado para a apropriação seletiva, a outro patamar foi elevada. "Se a emulação consiste em certo mal-estar ocasionado pela presença manifesta de bens honoríficos e que se podem obter em disputa com quem é nosso igual..." (ARISTÓTELES 2005, p. 192). Por fim, de modo preciso a distingue da inveja: "razão pela qual a emulação é uma coisa boa e própria de pessoas de bem, ao passo que a inveja é desprezível e própria de gente vil. Já o belo ensaio de João César indica o caráter restritivo dos conceitos de influência, imitação e plágio por meio de sua proposta de uma poética da emulação em Machado de Assis.

O dilema de Lezama Lima, muitas vezes minado por abordagens vinculadas à análise culturalista, é com a consciência científica, posto que o princípio objetivador entende de modo imediato submissão e recepção e, por fim, descarta a tradição como potencialidade de um saber. A possibilidade aberta por Lezama Lima em sua citação da emulação desloca seu conjunto de preocupações da epistemologia, entendido pelos vínculos de uma análise orientada por meio da subserviência metodológica. Há um compartilhamento entre a tradição e o volúvel desejo de invenção: sentir-se interpelado pela tradição. A mediação da tradição permite a emergência de diversas vozes do passado em ressonância permanente no mundo em que estamos fincados. Ao comentar a tradição pindárica e o mito da queda do homem, Lezama associa as inovações musicais do século com os principais dilemas da relação com o passado e da crítica à consciência histórica:

Sua modernidade é legítima porque, ao explorar desde a sua raiz a fonte da sua tradição, proclama adventícias as outras tradições decaídas ou impuras, servindo como suporte ou prova, pois uma tradição equivocada a expele, da mesma maneira que um corpo são rejeita as incorporações fragmentárias ou danificadas (LEZAMA LIMA 1957, p. 181).

Trata-se, desde as primeiras páginas do ensaio $A$ expressão americana, de um problema com a consciência histórica, tipicamente moderna, alicerçada no historicismo. Quando passa a considerar a legitimidade moderna, vocifera a revalorização da tradição para a compreensão e um modo de agir. Colocar-se na perspectiva da época estudada e pensar com conceitos e representações que lhe são próprias, sugere o "corpo são" que "rejeita as incorporações fragmentárias

\footnotetext{
${ }_{11}$ É importante notar que a figura da emulação encontra em David Hume destacável acolhimento: "a nobre emulação é fonte de toda excelência." In: "Do surgimento e progresso das artes e ciências" (HUME 2008, p. 83-97).

12 Alguns autores se dedicaram à emulação (LACAPRA 1989; CASTRO ROCHA 2013). Acredito que o argumento principal para Dominick LaCapra seja a sua importância para o reconhecimento como limite e possibilidade da hermenêutica. Já o belo ensaio de João César indica o caráter restritivo dos conceitos de influência, imitação e plágio por meio de sua proposta de uma poética da emulação em Machado de Assis.
} 
ou danificadas". Se o tempo, nesse caso, não é uma estrada a percorrer, apresenta-se enquanto uma senda, repleta de continuidades e sementes no caminho, formando uma tradição que ilumina aquilo que faz a sua aparição. Se uma das características fundantes do ensaísmo, mais do que a tão propalada subjetividade, é o jeito particular com que se equilibra a hermenêutica e a apresentação textual, Lezama Lima mais sugere do que define.. Permite que as "tradições decaídas ou impuras" sejam retiradas do "corpo são". Em outras palavras, a valorização da autorreferencialidade que indaga o humano por meio de uma conjunção indissociável entre a aporia do ser histórico e saber histórico. Dessa forma, Lezama Lima cumpre a função de compreender seu historiar ao entender sua historicidade no presente.

Enfatiza-se, nesse texto, o limite da noção de conhecimento histórico. Como no poema "The Dry Salvages" de T.S. Eliot, lido com atenção por Lezama Lima, que versa: "Como já se disse/A experiência vivida e revivida no significado/ Não é a experiência de uma vida apenas/ Mas a de muitas gerações - não se esquecendo/ Algo que, provavelmente, será de todo inefável:/ Olhar para além da certeza/ Da História documentada" (ELIOT 2004, p. 371). Como todo o poema trata do tempo como um problema central, envolto em caminhos e descaminhos da experiência humana, trata-se da busca de um instante de pacificação, almejado, contudo nunca alcançado, em que uma forma plena possa ser alcançada "No momento em que não é de ação nem inação" (ELIOT 2004, p. 373).

Seu escrito é uma alegoria de um mundo em extravio, que possui uma herança, mas que a vive como um processo permanente de declinação - musical, caso o leitor me permita. Esse legado deve ser compreendido como um ponto de acolhimento e endereçamento de uma escrita que marca a indecidibilidade acerca da descontinuidade e continuidade de categorias como literatura, filosofia, história, artes, América, natureza e homem. Seu livro mais rico (confesso!) investe em uma linguagem ordinária que trabalha com remissões, e não decisões, que se efetivam em âmbito espacial, mas que expressam riqueza por meio de sua indeterminação literária. Nessa via, até mesmo o empirismo não deixa de se mostrar enquanto falácia do conhecimento. América, ou vida, não poderiam ser mais do que suscetíveis ao que se apresenta como intangível e inatingível pelo conhecimento herdado. O mundo é inabordável, como se o leitor fosse o primeiro ou o último dos homens - ante a Selva, o lago Walden, ou qualquer espanto contemporâneo. A indeterminação americana deixa a modernidade como quadro aberto e sugere que nossa vivência sem fundamento é um crepúsculo que se quer amanhecer.

Iluminar os vínculos entre Lezama Lima e sua indagação pela tradição possibilita inseri-lo dentro de um amplo manancial de escritores para os quais a potencialidade de sua escrita não se coaduna com uma narrativa acerca de questões culturais. A solidão individual, ou seja, o fundamento de sua leitura, não reside na transmissão de valores culturais ou de posicionamentos políticos vinculados ao engajamento ou afastamento, mas ganha interesse justamente porque transcende os limites culturais e amplia nossa percepção daquilo que nomeamos humano. 


\section{Referências bibliográficas}

ADORNO, Theodor W. O Ensaio como Forma. In: Notas de literatura

I. São Paulo: Editora 34, 2003.

ANKERSMIT, F.R. History and Tropology. Baltimore, 1994.

. Historiografia e pós-modernismo. Topoi, Rio de Janeiro, v. 2, p. 113135, jan-jun. 2001.

. O uso da linguagem na escrita da história In:

A escrita da

história. A natureza da representação histórica. Londrina: EdUel, 2012. p. 33- 62 .

ARENDT, Hannah. A tradição e a época moderna. In: . Entre o passado e o futuro. São Paulo: Ed. Perspectiva, 2002.

ARISTÓTELES. Arte poética. Retórica. Tradução de Manuel Alexandre Júnior. Lisboa: Centro de Filosofia da Universidade de Lisboa/Imprensa Nacional, 2005. Disponível em: http://www.obrasdearistoteles.net.

BIRKENMAIER, Anke. Alejo Carpentier y la cultura del surrealismo en América Latina. Madrid: Iberoamericana, 2006.

BÜRGER, Peter. Teoria da vanguarda. Alto dos Moinhos: VEGA, 1993.

CALINESCU, Matei. Five Faces of Modernity: Modernism, Avant-Garde, Decadence, Kitsch, Postmodernism. Durham: Duke University Press, 1921987.

CAMPOS, Haroldo. O sequestro do barroco na formação da literatura brasileira: o caso Gregório de Matos. São Paulo: Iluminuras, 2011. - Barroco, neobarroco e transbarroco. Zunái - Revista de Poesia \& Debates. mar. 2002. Disponível em: http://www.revistazunai.com/ ensaios/haroldo_de_campos_transbarroco.htm. Acesso em: 20 abr. 2014.

CARPENTIER, Alejo. "América ante la joven literatura europea" presente em Carteles. La Habana, 28 jun. 1931.

El reino de este mundo. Santiago de Chile: Ed. Obras, 1972 [1948]. Los pasos perdidos. Madrid: Cátedra, 1985 [1955].

CURTIUS, Ernst Robert. Literatura europeia e Idade Média latina. Tradução de Teodoro Cabral. São Paulo: Edusp, 2013.

CHIAMPI, Irlemar. A História tecida pela imagem. In: LIMA, Lezama. A expressão americana. São Paulo: Brasiliense, 1988 [1957].

Barroco e a modernidade. Ensaios sobre literatura latino-americana. São Paulo: Perspectiva, 1998.

ELIOT, T. S. Four Quartets. In: Obra Completa. Vol I - Poesia. Tradução, Introdução e notas Ivan Junqueira. São Paulo: Arx, 2004 [1936]. 
. Tradition and Individual Talent (1919). Londres: Faber \& Faber, 1932.

HABERMAS, Jürgen. O discurso filosófico da modernidade. São Paulo: Martins Fontes, 1988.

HUME, David. Do surgimento e progresso das artes e ciências. In: A arte de escrever ensaio. Tradução de Marcio Suzuki e Pedro Pimenta. São Paulo: Iluminuras, 2008.

JARDIM, Eduardo. A duas vozes. Hannah Arendt e Octavio Paz. Rio de Janeiro: Civilização Brasileira, 2007.

KOSELLECK, Reinhardt. Futuro pasado: para una semántica de los tiempos históricos. Barcelona: Paidós, 1993.

LACAPRA, Dominick. History and Criticism. Ithaca: Cornell University Press, 1982.

Rethinking Intellectual History: Texts, contexts, language. Ithaca: Cornell University Press, 1983.

. History, Politics and the Novel. Ithaca: Cornell University Press, 1989.

LEZAMA LIMA, José. A expressão americana. Tradução de Irlemar Chiampi. São Paulo: Brasiliense, 1988 [1957].

Paradiso. Brasiliense, 1987.

LUKÁCS, Georges. L'ame et les formes. Paris: Gallimard, 1974.

MONTAIGNE, Michel De. Essais. Paris: Gallimard, 1965. 3 vols.

ROBYN, Ingrid. Rostros del reverso. José Lezama Lima en la encrucijada vanguardista. Austin: University of Texas Press, 2012.

ROCHA, João Cezar de Castro. Machado de Assis: por uma poética da emulação. Rio de Janeiro: Civilização Brasileira, 2013.

RORTY, Richard. The Linguistic Turn: Recent essays in philosophical method. Chicago: University of Chicago Press, 1967.

SKIRIUS, John. El ensayo hispano-americano del siglo XX. $3^{a}$ ed. México: Fondo de Cultura, 1994. 